\title{
Exploration and Practice of First-class Undergraduate Major Construction Under the Background of New Liberal Arts
}

\author{
Zhang Ziyan ${ }^{1,}$ Yang Zhe ${ }^{1,}$ Hu Wenbo ${ }^{2 a^{*}}$ Liu Zhaohui ${ }^{3 b^{*}}$ Li Ying $^{4}$ \\ ${ }^{1}$ Visual Communication Design Department, Hainan Tropical Ocean University, Sanya, China \\ ${ }^{I}$ International Cooperation Department, Hainan Tropical Ocean University, Sanya, China \\ ${ }^{2}$ Visual Communication Design Department, Hainan Tropical Ocean University, Sanya, China \\ ${ }^{3}$ Visual Communication Design Department, Hainan Tropical Ocean University, Sanya, China \\ ${ }^{4}$ Visual Communication Design Department, Hainan Tropical Ocean University, Sanya, China \\ ${ }^{5}$ Visual Communication Design Department, Hainan Tropical Ocean University, Sanya, China \\ $a^{*}$ Corresponding author.Email: 355798799@qq.com \\ $b^{*}$ Corresponding author.Email: liz9992021@163.com
}

Hint: Both Zhang Ziyan and Yang Zhe are the first authors.

Both Hu Wenbo and Liu Zhaohui are corresponding authors.

\begin{abstract}
According to cultivate the country needs of high-quality talent and contrast new arts construction requirements of Chinese higher education connotation development, this paper is taking visual communication design major of Hainan Tropical Ocean University as an example to discuss the talent training mode reformation, the project of talent fostering innovation, teaching resources and teaching staff construction optimization in local art design major, in order to break through the tradition, improve the education quality and build first-class undergraduate major.
\end{abstract}

Keywords: New liberal arts, First-class undergraduate major, Visual communication design

\section{INTRODUCTION}

New arts are relative to the traditional arts, on the basis of the global new revolution of science and technology, economic development and socialism with Chinese characteristics into a new era. It breaks the traditional thinking mode of liberal arts and promotes multidisciplinary cross and depth fusion in the way of inheritance and innovation, cross and integration, coordination and sharing for promoting the renewal of traditional arts. It transforms from subject-oriented to demand-oriented, from professional segmentation to cross-integration and from adaptive service to support and guidance. The concrete measures of the construction of new liberal arts mainly include concept reconstruction, structure transformation and mode reconstruction. To explore the cross integration of "arts, science and technology" and implement the "new" concept in all aspects of professional construction with internet thinking. It should consider the future society, restart cognition and reconstruct professional ecology. The construction of new liberal arts should emphasize the agglomeration advantages of "big and strong" and Chinese characteristics in subject development to meet the requirements of Ministry of Education on first-class major construction, which are to build for the future, to adapt to the demand, to lead the development, and to advance powerful guarantee first-class professional as the goal [1].

\section{ORIENTATION OF VISUAL COMMUNICATION DESIGN MAJOR UNDER THE BACKGROUND OF NEW LIBERAL ARTS}

\subsection{Major orientation}

Visual communication design major in accordance with the national standards for the class teaching of undergraduate course of common colleges and universities, as well as the college of Hainan Tropical Ocean university general school-running orientation, educational philosophy, and overall goal of personnel 
training. It adopts to the industry development trend and professional education development actively, trying to establish application-oriented disciplines that are in line with the development of the Times based on market demand, students' employment, and local businesses' requirements. Secondly, the major combines with the local industrial structure and is oriented to the society and enterprises, so that students can become applied talents with theoretical knowledge and practical ability of design and adapt to the needs of market development. It is the fundamental task of universities and colleges to insist on the cultivation of talents and the basic responsibility of teachers to teach and educate people based on the needs of social and economic development, in which moral education runs through the whole process of educational and teaching activities. Putting the cultivation of the students' practice ability and innovation ability in the important position of teaching while making teaching reformation direction, teaching design, teaching implementation and teaching evaluation by meeting the requirements of the state, society, and enterprises as the standard, and adjusting measures to local conditions for the needs of economic and social development of Hainan province applied talents with high quality [2]. Through the modern design transformation of Hainan ethnic folk traditions and Marian cultural resources, the major should complete the brand and industry transformation practice for social recognition with the integration of cross-border integration ability and systematic design thinking application-oriented artistic design compound talent.

\subsection{Professional training objectives and service orientation}

The major of visual communication design adheres to the fundamental task of moral cultivation, and aims to cultivate high-level artistic and cultural creative talents with social responsibility, innovative spirit, and practical ability, as well as top-of-the line artistic talents with broad international vision and the courage to take on heavy responsibilities.

The program is based on the economy and culture of Hainan Free Trade Port, and is oriented to the fields related to graphic design and modern digital media. It aims to cultivate high-quality application-oriented talents with all-round development of morality, intelligence, body, aesthetics and labor, strong learning ability and practical ability, innovative spirit, and in line with the needs of national economic and social development. Firstly, the major should be employment-oriented and the goal of talent training should be established. In addition, the focus of professional personnel training mode should be on mastering new knowledge and new technology with practical ability and the ability to solve practical problems. According to the orientation of applicationoriented talents training, the four major education curriculum systems of personal quality, specialty practice and innovation, and entrepreneurship are combined. Secondly, the major is centered on market demand, based on ocean and regional culture, cultivating scientific and rational spirit, leading aesthetic judgment, systematically mastering the basic theory and related skills of visual communication design, and mastering the basic skills of modern information technology application and design expression [3]. The major takes the goal of cultivating high technology and strong ability as the starting point, and divides the curriculum system into three modules, namely basic, development and research according to the planned content, in order to meet the requirements of student at all levels for different aspects of knowledge.

\section{PRESENT SITUATION OF COMPREHENSIVE REFORM OF VISUAL COMMUNICATION DESIGN MAJOR IN HAINAN TROPICAL OCEAN UNIVERSITY}

Visual communication design embraces innovation driven development, made in China 2025, Internet + , the public entrepreneurship innovation, Hainan free trade area (port) and other major national strategy. It takes the initiative to adapt to the new normal economic development, actively integrate into the development of industry transformation and innovation, as well as Chinese high education development and reform trend, for promoting quality education as the theme [4]. Secondly, starting from the needs of social and economic development, reasonable determination of professional training objectives, results-oriented, professional demonstration as the standard, visual communication design strives to achieve professional chain and industrial chain relative connection, curriculum content and professional standards relative connection, teaching process and production process relative connection for an overall optimization of training programs. Finally, to enlarge students' autonomous learning, the right of independent development space, provide students with diversified personnel training mode and the corresponding course system and teaching content, teaching method, course design advantage characteristics, will be fully integrated into the modern information technology teaching for promoting teaching knowledge, online support, extensive application of online teaching monitoring.

Based on the basic requirements of the construction of new liberal arts, the visual communication design major of Hainan Tropical Ocean University has made some achievements in the construction of curriculum system, construction of teaching staff and professional teaching quality assurance system. 


\subsection{Construction of professional curriculum system}

The program aims to cultivate high-quality application talents with all-round development of morality, intelligence, body, and aesthetics, in line with the needs of the innovation era, and with strong learning ability, practical ability and innovation ability. Professional training students should have the good thought personal character, outstanding practice ability and innovation consciousness, good communication skills and good team spirit, based on regional culture in Hainan, Hainan economic development, outstanding in tourism, convention and exhibition industry and domestic corporate branding. Students should have a strong sense of responsibility, scientific and rational spirit, leading aesthetic judgment, systematic professional knowledge. They should master the corresponding design thinking, expression, communication, and management skills, and be able to engage in design research and development, promote professional development, undertake design education and related research work, and could start their own business.

All of which will cultivate high-level applicationoriented art and design talents to meet the needs of China's socialist modernization, and interdisciplinary application-oriented talents to meet the needs of national social, economic, and cultural development.

\subsection{Teaching construction and reform}

\subsubsection{Major construction}

Creative design institute attaches great importance to the first-class undergraduate cultivation and application of construction points of work. According to the Ministry of Education of the implementation of first-class undergraduate specialty construction of "double than plan", the institute will hold meetings for first-class professional construction each two consecutive years, organize major discussion meetings and first-class professional judges with relevant units, coordinate and guide the professional to review the text and format of application materials to ensure the quality of application for first-class professional construction sites[5].

Table 1: Grade 2021 undergraduate major training program credits statistics

\begin{tabular}{|l|l|l|l|}
\hline Subject & $\begin{array}{l}\text { Proportion of } \\
\text { credits for } \\
\text { compulsory } \\
\text { courses (\%) }\end{array}$ & $\begin{array}{l}\text { Percentage } \\
\text { of credits for } \\
\text { elective } \\
\text { courses (\%) }\end{array}$ & $\begin{array}{l}\text { Practice } \\
\text { teaching } \\
\text { credit ratio } \\
(\%)\end{array}$ \\
\hline $\begin{array}{l}\text { Fine } \\
\text { Art }\end{array}$ & $75 \%$ & $25 \%$ & 16.8 \\
\hline
\end{tabular}

Hint: Students should take no less than 160 credits in total, including 120 credits for compulsory courses and 40 credits for elective courses.

\subsubsection{Transformation of education}

The program actively implements the spirit of the 2020-2021 undergraduate talent training work conference, closely centering on the overall idea of undergraduate talent training reform of "talent training mode reform, high-quality education and teaching resources construction, talent training system and mechanism reform" to promote the construction and reform of undergraduate teaching. The first is to explore more advanced teaching methods according to the training objectives of talents. Diversified teaching methods in teaching practice will be carried out, including establishing the dominant position of students in class, increase the degree of interaction between teacher and students, the reasonable use of heuristic teaching, etc. The goal is to cultivate the students' practice ability by enhancing their professional competence. In the learning process, students should first understand the position and application field of the course in the whole professional system, and expand their overall understanding of the professional field and work environment to acquire professional knowledge and skills related to the job. Through the design of science education, the theoretical knowledge is combined with practical skills, professional ability and professional quality, and the curriculum is refined according to the specific learning situation and task, so as to effectively improve the quality of talent training [6].

\subsection{3 "Internet plus innovative talent training" plan}

With top innovative talents as the core and innovative talent training as the main task, the design teaching of visual communication closely follows the reform process of colleges and universities across the country. It meets the challenge of the integration of learning and practice, and gradually and effectively promotes the transformation of teaching mode of visual communication design in colleges and universities. The current teaching methods and concepts of design courses are relatively behind first-class universities. The major is also actively exploring the reform direction to make visual communication design more practical and become a real discipline. In addition, the major should actively use advanced information technology to improve the modernization level of education and training. Through the application of advanced information technology, the problems existing in traditional education can be solved effectively and the purpose of improving the effectiveness of education can be achieved. The major actively promotes the reform of "internet plus" teaching and learning model reply on the construction of provincial-school quality projects and educational reform projects. The institute organized the application of three university-level open online course construction projects, and determined Moodle and Superstar Learning Pass 
online teaching platforms as supporting platforms of the university's "Internet Innovative talent training". At the same time, the institute actively organized online open course teaching design, online open course teaching application, online teaching activity design and skills training based on Moodle platform in order to help teachers gradually master the hybrid teaching mode combining online and offline, and steadily promote the reform of classroom teaching methods.

\section{CHARACTERISTIC DEVELOPMENT}

\subsection{Build a professional talent training system for art education}

With orientalism of visual art as the core and selfconstruction of Hainan culture as the main body, the discipline of visual art is continuously promoted. The major focuses on the core and ocean research direction, deepening the academic frontier and peak research, and constructing a multi-level training system to continuously help the construction of Hainan Free Trade Port. The establishment and construction of the specialty should be adapted to the regional economic development. The construction of the specialty can track and predict the development direction of the regional economy and the adjustment trend of the industrial structure, timely adjust the talent training program, and timely transport technical and skilled talents to local enterprises. Therefore, according to the national strategic positioning of Hainan Free Trade Island and the positioning of international tourism and consumption center, the visual communication design major should construct the tourism industry system of consumption, culture, exhibition, entertainment and so on, providing talent delivery for small and medium-sized enterprises accurately comply with the development trend of fine, personalized service.

\subsection{Optimize and strengthen the teaching staff for characteristic teaching team}

The construction of teaching team is the guarantee to improve the core competitiveness of the specialty and the key to the specialty construction. The specialty characteristic construction needs the characteristic teaching team as the foundation, the connotation of the teaching team lies in the construction of "double teacher" teaching team, with the backbone training as the support, structure optimization as the main line, in the form of pass-help-lead to train young teachers to have double teacher quality. First, visual communication design will update grade teachers' educational concepts through training and lectures, improve teachers' reform awareness and ability, and pay attention to the application of knowledge across disciplines. Secondly, to build up the idea of promote teaching by scientific research, quality, respect to the education scientific research as the main body, to the scientific research as the means of the principle, based on the conventional teaching scientific research policy. By giving play to the role of the guidance of the scientific research team, to enhance the level of scientific research and make scientific improvement on teachers' personal growth, in order to adapt to the talent training mode innovation and perfect the course system construction.

\subsection{Promote the construction of "new liberal - arts" talent training mode}

The reform of talent training mode is the key point of college education reform and the breakthrough point of characteristic specialty construction. The construction of new liberal arts is an important measure taken by the Ministry of Education and other relevant departments to implement the relevant instructions and requirements of General Secretary $\mathrm{Xi}$ Jinping, conform to the development trend of the new era and promote the convolution development of China's higher education. In the "14th Five-year plan" of the visual communication design major, the construction of "humanities as the body, science and technology as the application, art as the law", the major is exploring the construction of new liberal arts with the intersection and integration of "arts, science, and technology", and implementing the "new" concept in all aspects of the major construction with the Internet thinking. Therefore, the construction of the major should strive to carry out interdisciplinary, form and expand new knowledge fields on the disciplinary boundary, especially combine with science and technology, adapt to the new requirements of the development of philosophy and social science in the new era, and promote the intersection and integration of philosophy and social science with the new round of scientific and technological revolution and industrial reform. To sum up, the fundamental goal of higher education is to expand knowledge production and cultivate talents. Knowledge production and talent training are not only the basic content of teaching and research in colleges and universities, but also the real power to promote and enhance the development of colleges and universities.

\section{CONCLUSION}

The construction of new liberal arts is a vision for the construction of philosophy and social sciences under the background that the reform and opening of contemporary [7]. China has made great progress and the great rejuvenation of the Chinese nation has shown unprecedented bright prospects. It has a clear demand of The Times and at the same time bears profound historical responsibilities. The construction of new liberal arts focuses on building a system for cultivating liberal arts talents with Chinese characteristics and improving the quality of training liberal arts talents in an all-round way. 
The effect of professional construction is ultimately reflected in promoting the development of local economy and society. It is the value orientation of professional construction and the main way to form and consolidate the characteristics of the discipline to transform scientific and technological achievements into realistic productive forces to meet the needs of local economic and social development. Therefore, the goal and guiding ideology of the reform of talent training program are centered on market demand, oriented to the employment development of students, serving local enterprises, and establishing professional disciplines with unique characteristics in line with the development of The Times. Closely combined with the local industrial structure of Hainan, facing the society and enterprises, the students will become applied talents with theoretical knowledge and practical ability of design and adapt to the needs of market development.

\section{REFERENCES}

[1] Feng Cheng, Yang Zhao. (2021) Comparative study on policy supply of construction of world-class universities abroad [J]. Journal of higher education. pp.33-37.

[2] Chunmei Han, Yuzhuo Zhang (2020) Evolution logic and construction path of first-class disciplines under the background of "Double First-class disciplines" construction $[\mathrm{J}]$. Modern educational management, pp. 29-37.

[3] Yongjiang Wu, Connotation (2019). Appeal, and cultivation of university governance community under the background of double First-class Construction $[\mathrm{J}]$. Modern education and management. pp: 23-28.

[4] Hong Gong, Liang Chen (2019). The development of university's dominant characteristic subjects under the construction of "Double First-class" [J]. Modern education and management, pp.60-65.

[5] Cuiping Kang (2015). Three forms of university discipline construction and its policy construction [J]. Higher education research, pp: 37-41.

[6] Zhigang Zhou, Xiaohua Zong. (2021) The tendency of "target-only" school running and its regulation effect under the performance evaluation of double First-class construction in universities [J]. Exploration of higher education, pp. 40-46.

[7] Yanlong Guo. (2021) Research on the construction of Art design subject under the background of new liberal arts construction $[\mathrm{J}]$. Journal of Xichang College, pp. 105-108+118. 